\title{
Do participants in major, practice-changing breast cancer trials reflect the breast cancer patient population?
}

\author{
Shaun Treweek ${ }^{1 *}$, Ruth Dryden², Colin McCowan ${ }^{3}$, Alison Harrow ${ }^{2}$, Alastair Thompson ${ }^{2}$ \\ From 2nd Clinical Trials Methodology Conference: Methodology Matters \\ Edinburgh, UK. 18-19 November 2013
}

\section{Background}

Inadequate consideration of applicability is the most frequent criticism by clinicians of randomised trials, especially regarding narrow eligibility criteria.

\section{Aim}

To calculate how many women diagnosed with breast cancer between 1993 and 2008 in Tayside, Scotland, would have been eligible to participate in 12 major breast cancer trials.

\section{Methods}

Major trials were identified by reviewing phase III trials of adjuvant treatment referenced in recent national guidelines. This list was shortened by delegates at a meeting of the Scottish Cancer Trials Breast Group. Inclusion criteria for these trials were extracted from trial protocols and applied to women in the 16-year Tayside breast cancer dataset.

\section{Results}

33 breast cancer specialists ranked 39 trials in order of importance with the 12 most selected included in this study. Of 4811 women in the Tayside dataset, the number meeting eligibility criteria for the 12 trials ranged from $822(17 \%)$ to 3419 (71\%). Reasons for exclusion included age and comorbidity. Many women received a treatment evaluated in a trial but would themselves not have been eligible for the trial. For example, of 572 patients prescribed anastrazole and tamoxifen, only 281 were eligible for the trial evaluating that combination.

${ }^{1}$ University of Aberdeen, Aberdeen, UK

Full list of author information is available at the end of the article
Work to explicitly compare treatment decisions in clinical practice to trial eligibility criteria is ongoing.

\section{Conclusions}

Trialists should make their trials as widely applicable as possible. This may not have been the case for some major breast cancer trials, where women in the community receiving an intervention would not themselves have been eligible for the trial.

\section{Authors' details}

${ }^{1}$ University of Aberdeen, Aberdeen, UK. ${ }^{2}$ University of Dundee, Dundee, UK.

${ }^{3}$ University of Glasgow, Glasgow, UK.

Published: 29 November 2013

doi:10.1186/1745-6215-14-S1-P33

Cite this article as: Treweek et al:: Do participants in major, practice-

changing breast cancer trials reflect the breast cancer patient population? Trials 2013 14(Suppl 1):P33.

Submit your next manuscript to BioMed Central and take full advantage of:

- Convenient online submission

- Thorough peer review

- No space constraints or color figure charges

- Immediate publication on acceptance

- Inclusion in PubMed, CAS, Scopus and Google Scholar

- Research which is freely available for redistribution

Submit your manuscript at www.biomedcentral.com/submit 